\title{
FLUXOS IDENTITÁRIOS E AS RELAÇÕES DE PODER EM MOÇAMBIQUE
}

\author{
IDENTIFY FLOWS AND \\ POWER RELATIONS IN MOZAMBIQUE
}

Daniela de Brito ${ }^{1}$

\section{RESUMO}

Recorrendo às discussões em torno do conceito de identidade, este artigo procura esclarecer, por meio da trajetória das personagens, o modo como os romances Um rio chamado tempo, uma casa chamada terra, O outro pé da sereia e, principalmente, A varanda do frangipani, de Mia Couto, absorvem e desenvolvem a questão identitária, destacando a convivência entre grupos distintos e a tentativa do autor de estabelecer uma forma mais abrangente de abordar conflitos gerados pelas diferenças, estabelecidas, geralmente, por interesses de grupos dominantes.

PALAVRAS-CHAVE: Identidade; conflitos; diferenças.

\section{ABSTRACT}

By using the discussions around the concept of identity, this article intend to clarify, through the trajectory of the characters, how the novels Um rio chamado tempo, uma casa chamada terra, O outro pé da sereia, and, mainly, A varanda do frangipani, by Mia Couto, absorb and develop the identity issue, highlighting the coexistence among distinct groups and the author's attempt to establish a more comprehensive approach to conflicts generated by the differences, established, generally, by interests of dominant groups.

KEYWORDS: Identity; conflicts; differences. 
Desde o início do seu trabalho como escritor, Mia Couto combate a ideia de que existe uma essência africana, como muitos representantes de Moçambique insistem em reforçar. Segundo o autor, a África resulta de "diversidades e de mestiçagens" (COUTO, 2005, p. 60) e procurar a autenticidade africana apenas na tradição rural, ou considerar a modernidade dos centros urbanos como algo menos genuíno, intensificaria o afastamento das diferenças que, acolhidas e tratadas como positivas, poderiam colaborar para o autoconhecimento do país. Assim, Mia Couto (2005, p. 58-61) insiste em frisar que as comunidades são heterogêneas e dinâmicas.

Nesse percurso, não deixa de retratar a imagem, preconcebida nos tempos coloniais, da África como um lugar exótico, selvagem. E, ao mesmo tempo, preocupa-se com a problematização dessa imagem que, entre outros equívocos, caracteriza o africano de uma maneira, muitas vezes, errônea. O autor traz essas questões para o seu texto ficcional e o faz por meio de suas personagens. Ao mobilizar uma discussão em torno do que é ser africano, permite-nos entrever a negação do pressuposto de que o contato com uma cultura diferente implica a perda de qualquer coisa pura que o africano possa possuir, mantendo-se ligado apenas à tradição cultural africana. Pelo contrário, é justamente da mescla de etnias e culturas que o povo moçambicano está a se construir enquanto nação em formação. Sob tal perspectiva, deparamos com uma fala de Arcanjo Mistura, em O outro pé da sereia, quando se recusa a participar de uma cerimônia tradicional realizada por Lázaro: - Para sermos africanos não temos que passar por isto, disse com desdém. Vivo sem dúvidas nem dívidas, reiterou-se à despedida. (COUTO, 2006, p. 277).

A personagem Arcanjo não concorda com a atitude dos companheiros de quererem dar vazão à imagem que os dominadores criaram dos africanos, defende que não necessitam, nem devem, recorrer a esse subterfúgio, nem a quaisquer outros, para serem considerados africanos. Arcanjo conhece seu lugar de pertença e não precisa se afirmar como africano autêntico, não tem de provar nada para os outros, aliás, na mesma direção, diz para Benjamin que os negros têm de se desvincular da categorização de ser negros e se constituírem como pessoas íntegras, não podem continuar reféns da cor da pele, um denotativo fulcral da diferença racial e cultural. Para Arcanjo, é necessário que os negros atravessem os limites impostos pelo discurso racial e teçam seu próprio caminho, por mais tumultuado que ele possa ser.

Trata-se de uma viagem de busca identitária que, no percurso ficcional de Mia Couto, entre outras veredas, faz-se presente ainda na trajetória de outras personagens que, enquanto se deslocam entre espaços físicos e/ou por meio da imaginação, indiciam as mudanças promovidas pelos trânsitos realizados no presente, sem deixar de expressar os conflitos causados pelos encontros ocorridos no passado. Um passado que não desaparece, pois, em conformidade com Mata (2003, p. 49), no pós-independência literário, na fase em que já bastante diminuída a tendência 
panfletária, manifesta-se ainda um momento marcado pelo dilema acerca da expurgação dos espaços coloniais, visto que a presença colonial ainda incomodava, o que é corroborado pelo que aponta Cabaço (2009, p. 320) em termos históricos: "A independência, que marca o fim da 'situação colonial', não representa, de facto, a ruptura 'radical' com a sociedade colonial.". Resquícios da colonização perduram na sociedade moçambicana e não podem ser apagados ou negados.

Não dá para fechar os olhos para a influência lusitana no território africano, da mesma forma que os portugueses residentes em Moçambique também deixaram se entranhar pelos costumes africanos. Há, desse modo, servindo-nos das palavras de Bhabha (1998, p. 22), um espaço “[...] intersticial entre identificações fixas [que] abre a possibilidade de um hibridismo cultural que acolhe a diferença sem uma hierarquia [...]”. Espaço intervalar em que ocorre a aproximação e a inter-relação das diferenças culturais, no entanto, é necessário frisar que o acolhimento dessas diferenças não representa a inexistência de conflitos.

Em A varanda do frangipani (2007), por exemplo, essa integração pode ser percebida no entrosamento que se estabelece entre o velho português Domingos Mourão e os idosos moçambicanos que habitam o asilo, mas, paralelamente, as desavenças não deixam de existir, como se detecta em um enfrentamento entre Mourão e Nhonhoso, em que o embate entre brancos e negros vem à tona:

- Você sempre quer mandar em mim. Sabe de uma coisa: colonialismo já fechou!

- Não quero mandar em ninguém...

- Como não quer? Eu nos brancos não confio. Branco é como camaleão, nunca desenrolam o rabo...

- E vocês, pretos, vocês falam mal dos brancos mas a única coisa que querem é ser como eles...

- Os brancos são como piripiri: a gente sabe que comeu porque nos fica a arder a garganta.

- A diferença entre mim e você é que, a mim, ficam cabelos no pente enquanto a você ficam pentes no cabelo.

$[\ldots]$

- Eh pá, Xidimingo, estou-lhe a agradecer bastante.

- Porquê?

- Charra! Eu quase ia morrer sem bater um branco.

- Chamas a isto bater? Recebi foi carícias... (COUTO, 2007, p. 62).

Domingos impede que Nhonhoso corte a árvore do frangipani, agredindo-o fisicamente, o que é visto como uma afronta pelo moçambi- 
cano, tanto que ele se expressa como se tivesse sido colocado na posição de colonizado. Esse fato é ressaltado ainda pela réplica do português que, novamente, é rebatida pelo velho africano. O preconceito contra o branco é explicitado por Nhonhoso, que os considera traiçoeiros, enganadores. $\mathrm{Na}$ sua tréplica, Domingos aponta para uma questão delicada da colonização, e trazida por Franz Fanon, em Os condenados da terra (1969, p. 38), que é a inveja e, ao mesmo tempo, a repulsa que o negro sente do branco colonizador, lembrando que o negro não deseja ser o colonizador, deseja assumir o seu lugar. O que é corroborado pelo fato de Nhonhoso adotar uma postura ofensiva para falar dos brancos, insinuando que o que os colonizadores fizeram permanece na lembrança dos que foram colonizados e ainda tem repercussão.

Os idosos são amigos e a briga termina em brincadeira, no entanto, percebe-se a existência de tensões raciais entre eles que, no momento da discussão, referem-se um ao outro pela cor da pele, destacando o aspecto que no antigo colonialismo era usado para diferenciar o homem superior ou civilizado do homem inferior ou primitivo e que justificava a dominação de um pelo outro. Porém, o português também se sente ofendido com o que houve entre ele e o amigo, porque, como não é um branco colonizador, os insultos de Nhonhoso não lhe cabem. As divergências entre Nhonhoso e Mourão, finalmente, acabam por ser relativizadas, uma vez que todos os idosos estão na mesma condição de isolamento, abandono e degradação, advindos, sobretudo, das consequências da guerra civil que se instalou no país após a Independência. Percebe-se que o conflito colonizador versus colonizado ainda perpassa os contatos mantidos entre brancos e negros, porém, não tem mais a eficácia que apresentava anteriormente.

Mesmo marcado como carrasco dos idosos de São Nicolau, Vasto também é vítima de preconceito e descaracterização, como relata Marta:

Vasto se sentia traído. Os melhores anos de sua vida ele os dera à revolução. O que restava dessa utopia? No início se descontaram aparências que nos dividiam. Com o tempo lhe passaram a atirar à cara a cor da pele. O ele ser mulato esteve na origem daquele exílio a que o obrigavam. (COUTO, 2007, p. 125).

Vasto sofre um processo de despersonalização, porque, além de ser visto como inferior aos negros, os responsáveis por colocá-lo nessa situação são os mesmos que lutaram por igualdade e defenderam a liberdade, combatendo, em seguida, as diferenças étnicas. São os negros que, agora, estabelecem um projeto de homogeneidade, de pureza, que, geralmente, era definido pelo colonizador. Nota-se que a enfermeira traz um questionamento que aponta um duplo sentido, uma vez que a utopia tanto pode se referir a Vasto quanto à revolução. $\mathrm{O}$ que foi feito do sonho do diretor do asilo e da própria revolução? Desapareceu, visto que, em ambos os casos, os aspectos do colonialismo não se extinguiram com a Independência de Moçambique. 
Mais ainda, são aspectos que interferem no percurso do moçambicano e do país, onde o espaço deixado pelos portugueses é ocupado pelas autoridades negras que, entretanto, atuam de modo muito semelhante ao dos colonizadores. Autoridades que recusam a heterogeneidade e se desviam de seu projeto de construir uma nação autônoma que, segundo Cabaço (2009, p. 297), acolha todos os moçambicanos, sem diferenciações. Assim, vendo-se ludibriado pelos seus, Vasto tem sua utopia transformada em ressentimento e despeito, descarregando-os na violência contra os mais fracos, ou seja, passa a empregar o mesmo método empregado contra ele: o preconceito. Preterido pelos negros, Vasto procura combater de forma mais veemente o que poderia associá-lo à sua ascendência branca; nega-se como mulato, tentando afirmar-se como negro. Por não ter a cor da pele dos negros, em um país de maioria negra que lutava pelo controle político, procurando banir até mesmo seus conterrâneos mestiços, Vasto é visto como um resquício da colonização, e tenta negar sua miscigenação, penalizando principalmente o português que, por sua vez, distancia-se do papel de dominador que Vasto quer lhe imputar.

A imagem distorcida que Vasto tem, especialmente a seu respeito, imagem que lhe foi imposta pelos representantes de seu próprio país e que colabora para a continuidade de um sistema de dominação que mantém o africano em uma posição de inferioridade, alegoriza a situação em que se encontra Moçambique após a Independência. Na construção do universo ficcional, a representação da imagem de Vasto é estrategicamente elaborada como elemento de fluxo identitário em que se mostra que as tensões raciais não se dissolveram após o encerramento do sistema colonial, uma vez que os modos de encenação das identidades continuam atravessados por vestígios desse sistema, o que torna necessária, conforme explicita Appiah (1997, p. 249), “[...] a desarticulação do discurso das diferenças 'racias' e 'tribais', pois [...] a realidade dessas muitas identidades rivais da África de hoje faz o jogo, justamente, dos exploradores de cujos grilhões estamos [os africanos] tentando escapar.”.

Marta, por sua vez, é a personagem feminina que rompe com a padronização geralmente feita da mulher negra africana. Em trânsito identitário, ela mesma explicita seu deslocamento: “[...] fui educada como assimilada. Sou de Inhambane, minhas famílias já há muito perderam seus nomes africanos. Sou neta de enfermeiros. A profissão me reaproxima da família que eu há muito perdera." (COUTO, 2007, p. 123). Marta define-se como alguém que traz traços provenientes dos portugueses e outros que são nitidamente seus, de sua família moçambicana, mas esta também já foi descaracterizada e Marta tenta preservar o legado de seus antepassados. O abandono dos idosos, para ela, é algo associado a um "golpe de Estado" contra o passado, que ocorre no asilo e em todo o país. Além de demonstrar consciência em relação à sua condição individual, Marta também revela ter noção da situação por que passa o país, remetendo-nos ao que diz Francisco Noa, em Império, mito e miopia (2002, p. 309), sobre os assimila- 
dos: “[...] culturalmente híbridos, são eles que acabam por estar no centro do descontentamento e por fazer implodir uma verdadeira e aguda crise de identidade individual e coletiva... Marta tenta desestabilizar o jovem Izidine Naíta, questionando-o ou provocando-o quanto ao distaciamento ou à perda da identidade moçambicana do policial.

Embora se diferencie de Marta, Ermelindo Mucanga é mais uma personagem de $A$ varanda do frangipani (2007) que se delineia como assimilada: "Sempre estudara em missão católica. Me tinham calibrado os modos, acertadas as esperas e as expectativas." (COUTO, 2007, p. 114). $\mathrm{O}$ deslocamento identitário da personagem revela-se no embate entre a forma como foi moldado e aquilo que seria genuíno nele. Sua maneira de pensar sofreu alterações, visto que suas crenças e costumes foram ajustados de acordo com a perspectiva de visão do colonizador. Ajuste eficaz, considerando-se que Ermelindo, durante o período colonial, trabalha para os portugueses na construção de uma prisão para os negros e, quando acusado de "[...] traidor, carrasco dos justos" (COUTO, 2007, p. 115), lança um olhar de desdém para os seus semelhantes. Sua morte, ocorrida às vésperas da Independência, é significativa, principalmente pelo modo como é narrada: "Fazia a piada: meu país nascia, em roupas de bandeira, e eu descia ao chão, exilado da luz." ( COUTO, 2007, p. 10). No momento da revolução libertadora, da euforia do projeto de construção de uma nação autônoma, não havia espaço para nada que compactuasse com o dominador, tudo aquilo que estava associado ao colonizador tendia a desaparecer, tinha que ser morto e enterrado. De fato, lembra uma "piada" ou, mais especificamente, trata-se de uma ironia, pois, vinte anos depois, aquilo que se tentou esquecer ou eliminar reaparece, afinal, Ermelindo volta à vida e mostra o que ocorreu com essa nação que se sonhava tão livre do passado colonial. Ele não aceita ser transformado em objeto manipulado pelas autoridades atuais para camuflar a verdadeira situação do país; não admite ser alçado à imagem de herói criada pelos novos dirigentes, por isso se rebela, retornando ao mundo daqueles que ainda padecem com as agruras da guerra civil.

Essas agruras, sob uma perspectiva um pouco diferente, mas também relacionada à indefinição da identidade do país, porque ainda em processo de formação, fazem-se presentes em Um rio chamado tempo, uma casa chamada terra (2003), manifestando-se por meio de tensões decorrentes do convívio de etnias diversas. Um desses conflitos envolve a personagem Ultímio, negro preconceituoso que pertence à elite e se julga superior, desconsiderando, de um modo geral, aqueles que não são negros ou ricos como ele, deixando entrever seu preconceito:

- Metade do seu sangue é de branco.

Ultímio nega, ajuntando os pés, cruzados os dedos. Primeiro ri-se. Depois, se faz sério e pede a Abstinêncio que confime: - Você, o mais velho, comprova? 
- É verdade, sim, Ultímio.

- Não acredito. Isso me dizem agora, que estou traumartirizado. (COUTO, 2003, p. 215).

O fragmento delineia o ridículo da reação exagerada de Ultímio ao saber que seu sangue não é puramente negro, devido a uma transfusão feita na infância e que salvou sua vida. De vítima, Ultímio não tem nada, em compensação, coloca-se no lugar do sofredor, no que observamos conter, implicitamente, uma zombaria em relação à sua postura equivocada, acentuada pelo neologismo "traumartirizado", que, em vez de atribuir um tom dramático à sua fala, produz um efeito inverso, tornando-a cômica. Esse efeito tragicômico, de certo modo, caricaturiza a personagem, caricaturização também reveladora de pormenores que o situam em uma posição patética, posto que até mesmo seus trejeitos, gestos físicos, são baseados em superstições (cruzar dedos, juntar pés) esvaziadas de sentido, tanto quanto o seu preconceito desmesurado.

A trajetória romanesca de Ultímio é ainda permeada por episódios que acentuam o olhar crítico lançado sobre ele, que, explorador das riquezas naturais da Ilha, sobrecarrega de madeira o meio de transporte da população. Ironicamente, é um acidente por excesso de peso, ocorrido no barco usado para seus negócios escusos, que o expõe, novamente, a uma situação em que depende daquele que menospreza, neste caso, o médico indiano da Ilha:

Enquanto Amílcar Mascarenha se ocupa dos curativos, Ultímio vai falando:

- Esta noite nem dormi com essa história do sangue. É verdade, doutor, que me deram sangue de branco?

- Não sei o que é isso.

- Não sabe o que é o quê?

- Sangue de branco.

Ultímio se arruma melhor na cama, soerguendo-se nas almofadas. Recusa a ajuda do médico, recupera o fôlego e, de novo, se dirige a Mascarenha:

- Eu gosto de si. Mas o meu ódio por si é muito mais antigo que eu.

- Está a falar de mim ou de minha raça?

- Lamento, doutor, mas, para mim, você é a sua raça. (COUTO, 2003, p. 216-217).

É importante destacar, aqui, que Ultímio é a única pessoa a se ferir no incêndio, o que não é gratuito; tem-se a impressão de que esse acidente o faz provar de sua própria ganância, falta de escrúpulos e desonestidade. Esse episódio seria uma oportunidade para Ultímio colocar-se no lugar do outro, entretanto, como se vê na citação acima, o acidente é mais 
uma maneira de trazer à cena as ambiguidades que marcam essa personagem que, ao mesmo tempo em que tem aversão ao branco, assume postura muito semelhante à do colonizador europeu.

O médico indiano, diante de quem Ultímio também não disfarça seu incômodo, seu mal-estar e, novamente, sua atitude preconceituosa, debocha das palavras de Ultímio, ironizando a sua postura, pois Ultímio não enxerga que só sobreviveu em virtude do que ele categoriza, de forma imbecil, como "sangue de branco". Permeada pelo racismo indiscriminado, as frases finais de Ultímio acentuam o seu repúdio em relação a Amílcar, ao ver o médico não como um indivíduo, mas como um segmento racial. Segmento que, historicamente, em conformidade com as considerações de Cabaço (2009, p. 227), adquiriu uma acepção reificada, discriminatória e pejorativa, apagando ou diminuindo a individualidade. Vale salientar, contudo, que, se por um lado, Ultímio rejeita Amílcar, reduzindo-o a um conjunto de características que apenas o enquadram na sua raça, por outro, tem interesses econômicos em comum com os indianos, não os repelindo nesse caso. Ou seja, Ultímio ignora a diferença racial quando se trata de dinheiro, o que demonstra sua inescrupulosa parcialidade, manifestando, mais uma vez, um comportamento semelhante ao do colonizador branco que tanto despreza.

Em O outro pé da sereia (2006), por sua vez, delineiam-se diferentes tipos de deslocamentos identitários, tendo em vista que as personagens, de um modo geral, realizam viagens que indicam, utilizando-nos dos termos de Mata (2003, p.67), “[...] uma das marcas das culturas pós-coloniais: a sua hibridez, resultado de uma situação de semiose cultural ou de relação dialética entre matrizes civilizacionais diversas [...]”. Nesse trânsito, encontra-se o padre Manuel Antunes que, munido de um senso crítico apurado, na viagem oficialmente empreendida com o propósito de expansão da fé católica, toma contato com a realidade desumana a que os negros escravos, que estão no porão do navio, são expostos. À medida que a viagem para Moçambique progride, Manuel Antunes experimenta um deslocamento interno que o vai transformando:

Até o dia 4 de Janeiro, data do embarque em Goa, ele era branco, filho e neto de portugueses. No dia 5 de Janeiro, começara a ficar negro. Depois de apagar um pequeno incêndio no seu camarote, contemplou as suas mãos obscurecendo. Mas agora era a pele inteira que lhe escurecia, os seus cabelos se encrespavam. Não lhe restava dúvida: ele se convertia num negro.

- Estou transitando de raça, D. Gonçalo. E o pior é que estou gostando mais dessa travessia do que de toda a restante viagem. (COUTO, 2006, p. 164).

Ao explicitar, metaforicamente, o movimento de transfiguração pelo qual está a passar, firmando, de início, sua origem branca e europeia para, em seguida, por meio dos verbos no gerúndio ("obscurecendo", "tran- 
sitando", "gostando") especificar, passo a passo, a mudança racial que vai vivenciando, o padre Antunes parece alegorizar a mescla de etnias que começará a ocorrer com a chegada dos portugueses em África. E, diferentemente da padronização do branco colonizador, Antunes se deixa penetrar pelo "corpo" africano. O verbo "converter-se" acentua a metamorfose que se opera no padre que verbaliza, com serenidade e consciência, o sabor incutido no processo de internalização que se manifesta em seu ser.

Processo que o aproxima, em certa medida, da trajetória da personagem Nimi Nsundi, uma vez que, ao alcançar as terras africanas, Manuel Antunes incorpora o nome desse escravo que morrera durante a viagem, cujo sangue perdido antes de morrer: "[...] não era de um homem mas de todo um continente escravo" (COUTO, 2006, p. 314). A composição da imagem de Nimi é elaborada como um elemento de conjugação de aspectos ligados à escravidão, ao tráfico de escravos: a saudade de sua terra, para onde sabia que não retornaria, os castigos que recebe ao desobedecer uma autoridade colonial, a prisão em um porão de navio em condições sub-humanas e, principalmente, a sua morte dramática, levando-nos a considerá-lo como uma personagem alegórica.

Além disso, ao demonstrar consciência social e cultural, deixando registrado em uma carta o que os portugueses pensam a respeito dos negros, Nimi traz para o universo ficcional o discurso empregado pelos brancos para escravizar: “[...] dizem que não temos alma. Temos, eles é que não veem. $\mathrm{O}$ coração dos portugueses está cego. [...] É essa a razão porque D. Gonçalo da Silveira quer embranquecer a minha raça. Não é a nossa raça que os atrapalha: é a cor da nossa alma que eles não conseguem enxergar." (COUTO, 2006, p. 113). Nimi contém traços que o tornam uma espécie de porta-voz dos negros, principalmente porque assinala aquilo que, para o branco, engloba todos os negros, despersonalizando-os: a cor da pele. Mostra, ainda, que o que os brancos fazem com os negros é ainda mais grave: não o reconhecem como seres humanos, porque não conseguem enxergar o que está além da pele.

E, nesse sentido, a personagem Zeca Matambira, em princípios de século XXI, mostra que o discurso da inferioridade da raça negra ainda permanece, fazendo a personagem refém da sua cor de pele:

E recordou o creme para aclarar a pele, os produtos para desencrespar o cabelo, a ocultação da sua origem humilde. Sim, a sua existência tinha sido um permanente e nunca alcançado disfarce. [..] Era no pente, como num espelho, que ele contemplava a sua raça. [...] Ele era um preto, tão irreversivelmente negro como todos os de Vila Longe. Depois, limpava o pente como se a si mesmo se lavasse. Como se o cabelo fosse uma sujidade na alma, a irrefutável prova de um crime sem perfeição. (COUTO, 2006, p. 294).

Por meio do discurso indireto livre, a voz enunciadora penetra nos pensamentos de Zeca Matambira, revelando as reflexões dessa per- 
sonagem sobre as ambivalências que atuam nela, pois, ao mesmo tempo em que existe um esforço constante para alcançar o embranquecimento da pele, há a constatação da impossibilidade de deixar de ser negro. É um embate pungente, pois Matambira desqualifica-se de tal forma que chega a negar-se, afinal, negro e pobre, usa subterfúgios inoperantes para tentar esconder sua condição social. O gesto de Matambira de limpeza do pente, referindo-se a uma possível sujeira da alma, poderia ser relacionado à ideia, preconcebida e equivocada, vinda com os portugueses, de que os negros não têm alma, o que retomaria o que Nimi Nsundi diz na narrativa do século XVI.

Nessa perspectiva, na narrativa do século XXI, ecoa a caracterização que era dada aos negros que, como expõe Cabaço (2009, p. 102), “[...] os portugueses deram tanta ênfase ao conceito de 'limpeza' ou 'pureza de sangue', não só de uma classe mas também de uma perspectiva racial.. E, no que se refere à falta de "pureza", nota-se que ela é apontada pelo branco por meio de um aspecto físico particular do negro que, no caso de Matambira, é o cabelo crespo, e, no que traz Nimi, a cor da pele, isto é, emprega-se a parte pelo todo, em uma "sinédoque do despojamento", utilizando-nos das palavras de Noa (2003, p. 298).

É possível pensar também o quanto esse modo de definir o negro contamina Matambira, um pugilista bem-sucedido que, por não conseguir lutar boxe contra os brancos, abandonou a profissão: “[...] ele só era capaz de bater num negro, num homem de igual raça. A sua cabeça tinha sido ensinada a não se defender de um branco. Nem de um mulato." (COUTO, 2007 , p. 219). No comportamento de Matambira transparece, além da permanência, o poder devastador do discurso da diferença, visto que a personagem incorpora a imagem de inferioridade que o branco criou em torno do negro. Zeca Matambira não consegue transgredir os limites de sua aparência física, sendo dominado pelos preconceitos que ele mesmo reproduz.

Entre os diferentes cruzamentos que comparecem nessa obra, destacam-se ainda os que se manifestam por meio da personagem Rosie, que mistura em si as ressonâncias propiciadas pelo trânsito dos negros africanos pelo mundo, particularmente, aqueles cujo destino era o Brasil, onde os aspectos etno-culturais dos negros, apesar das dificuldades, conseguiram resistir, perdurar e multiplicar-se, transformando o território brasileiro em um espaço multicultural como o espaço de onde originavam esses africanos. Também Benjamin Southman comparece no romance como resultado de mesclas, afinal, é um mulato norte-americano, ou seja, sua mestiçagem flui entre o que o caracteriza como descendente de africanos e o que o configura como procedente de nativos dos Estados Unidos, seu país natal.

Em seu trajeto ficcional, Mia Couto não abre mão de apontar as divergências que a multiplicidade étnica e cultural promove, no entanto, também privilegia os trânsitos que propiciam a pluralidade identitária de Moçambique. Em O outro pé da sereia (2006), sem perder de vista os olhares lançados sobre a África e os africanos, aborda-se a questão do convívio 
e dos conflitos entre as diferenças: a trajetória de Manuel Antunes revela a transfiguração do branco em negro; o dia a dia de Zeca Matambira mostra o empenho desse negro em parecer branco. Em A varanda do frangipani (2007), por meio dos trânsitos identitários que ali se identificam, ganha destaque a figura de Domingos Mourão. E em Um rio chamado tempo, uma casa chamada terra (2003), embora exista uma dificuldade de articulação das diferenças por parte de personagens como Ultímio, que talvez se iluda com a possibilidade do que se considera uma identidade única ou pura, reiteração do modelo totalitário do colonizador, é ridicularizado, afinal, o que ele expressa revela-se inoperante, pois não é possível escapar aos contatos, já que os cruzamentos são inevitáveis.

\section{REFERÊNCIAS BIBLIOGRÁFICAS}

APPIAH, Kwame Anthony. Na casa de meu pai: a África na filosofia da cultura. Rio de Janeiro: Contraponto, 1997.

BHABHA, Homi. K. O local da cultura. Belo Horizonte: Editora UFMG, 1998.

CABAÇO, José Luís. Moçambique: identidade, colonialismo e libertação. São Paulo: Editora UNESP, 2009.

COUTO, Mia. O outro pé da sereia. São Paulo: Companhia das Letras, 2006.

A varanda de frangipani. São Paulo: Companhia das Letras, 2007.

Um rio chamado tempo, uma casa chamada terra. São Paulo: Companhia das Letras, 2003.

FANON, Frantz. Os condenados da terra. Prefácio de Sartre. Trad. José Laurêncio de Melo. Rio de Janeiro: Civilização Brasileira, 1968.

MATA, Inocência. A condição pós-colonial das literaturas africanas de Língua Portuguesa: algumas diferenças e convergências e muitos lugares-comuns. In: LEÃO, A.V. (Org.). Contatos e ressonâncias: literaturas africanas de Língua Portuguesa. Belo Horizonte: PUC Minas, 2003, p. 43-72.

NOA, Francisco. Império, mito e miopia - Moçambique como invenção literária. Lisboa: Editorial Caminho, 2002.

Recebido para publicação em 26/05/2018

Aprovado em 20/08/2018

\section{NOTA}

1 Doutora pela UNESP/Ibilce (2014). Pós-doutorado na UFSCAR - Universidade Federal de São Carlos (2017). E-mail: danidot2015@gmail.com 